UCRL-JC-114260

PREPRINT

\title{
Two-Gigawatt Burst-Mode Operation of the Intense Microwave Prototype (IMP) Free-Electron Laser (FEL) for the Microwave Tokamak Experiment (MTX)
}

B. Felker, S. Allen, H. Bell, J. Bowman, M. Delong, M. Fenstermacher, S.W. Ferguson, W.F. Fields IV, D. Hathaway, E.B. Hooper, S. Hulsey, M. Jackson, D. Lang, C. Lasnier, M. Makowski, J. Moller, W. Meyer, D.G. Nilson, D. Peterson, D.B. Seilhymer, and B. Stallard

This paper was prepared for submittal to the Proceedings of the 15th Symposium on Fusion Engineering Hyannis, MA

October 11-15, 1993

October 6, 1993

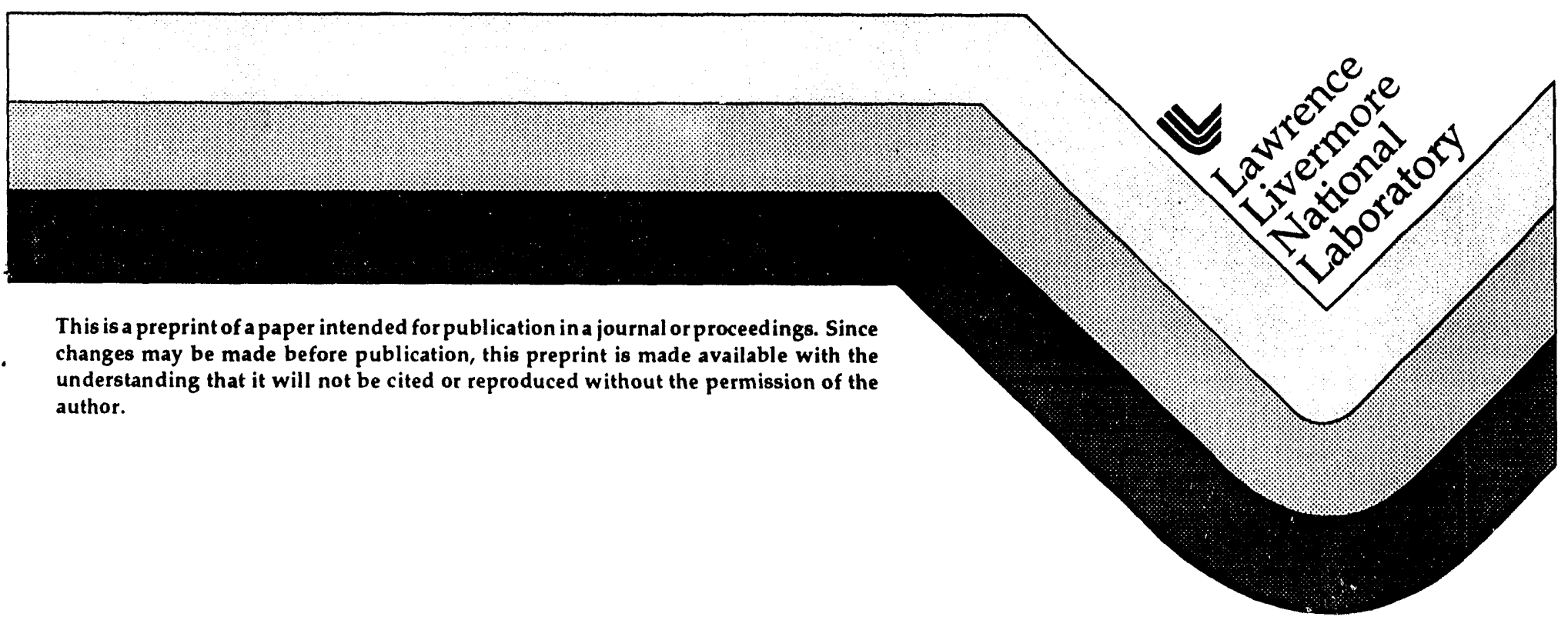




\section{DISCLAIMER}

Thlo document was prepared as an sccount of work sponsored by an agency of the Unlted States Goverament. Nelther the Undted Steties Government nor the Univeraity of Caltiforala nor any of thetr employees, makee any warranty, expres or baplled, or

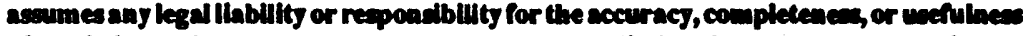
of any information, apparatus, product, or proceso dieclowed, or represents that its une would not infriage privately owmed rights. Reference berela to anj epecinic commercial products, proceses, or service by trade wame, trademarts, manufacturer, or olherwive, does not necesearily condttute or Imply lts endorsement, recommendation, or favoring by the Ualted States Government or the Uni veralty of Callfornila. The viows and oplations of authors expresaed herela do not necesearliy state or reflect those of the Uniled States Government or the Univeratty of Callforala, and shall not be wod for advertiding or 


\title{
TWO-GIGAWATT BURST-MODE OPERATION OF THE INTENSE MICROWAVE PROTOTYPE (IMP) FREE-ELECTRON LASER (FEL) FOR THE MICROWAVE TOKAMAK EXPERIMENT (MTX)
}

\author{
B. Felker, S. Allen, H. Bell, J. Bowman, M. Delong, M. Fenstermacher, S. W. Ferguson, W. F \\ Fields IV, D. Hathaway, E. B. Hooper, S. Hulsey, M. Jackson, D. Lang, C. Lasnier, M. Makowski, \\ J. Moller, W. Meyer, D. G. Nilson, D. Peterson, D. B. Seilhymer, B. Stallard, Lawrence Livermore
} National Laboratory, Livermore, California 94551-9900

would be accomplished without the need for power limiting windows and antenna structures near the plasma. The short

\section{ABSTRACT}

--The MTX explored the plasma heating effects of $140 \mathrm{GHz}$ microwaves from both Gyrotrons and from the IMP FEL wiggler. The Gyrotron was long pulse length ( 0.5 seconds maximum) and the FEL produced short-pulse length, high-peak power, single and burst modes of $140 \mathrm{GHz}$ microwaves. Full-power operations of the IMP FEL wiggler were commenced in April of 1992 and continued into October of 1992. The Experimental Test Accelerator II (ETA-II) provided a 50-nanosecond, 6-MeV, 2 - 3 kAmp electron beam that was introduced co-linear into the IMP FEL with a $140 \mathrm{GHz}$ Gyrotron master oscillator (MO). The FEL was able to amplify the MO signal from approximately $7 \mathrm{~kW}$ to peaks consistently in the range of $1-2 \mathrm{GW}$. This microwave pulse was transmitted into the MTX and allowed the exploration of the linear and non-linear effects of short pulse, intense power in the MTX plasma. Single pulses were used to explore and gain operating experience in the parameter space of the IMP FEL, and finally evaluate transmission and absorption in the MTX. Single-pulse operations were repeatable. After the MTX was shut down burst-mode operations were successful at $2 \mathrm{kHz}$. This paper will describe the IMP FEL, Microwave Transmission System to MTX, the diagnostics used for calorimetric measurements, and the operations of the entire Microwave system. A discussion of correlated and uncorrelated errors that affect FEL performance will be made. Linear and non-linear absorption data of the microwaves in the MTX plasma will be presented.

\section{INTRODUCTION}

The purpose of the MTX was to explore the technology of the FEL for use as an source of Electron Cyclotron Resonant Heating (ECRH). The Microwave Tokamak Experiment (MTX) began in 1987 with the removal of ALCATOR C from MIT and transportation of the majority of the equipment to Livermore. It was installed in Livermore, renamed MTX and made operational for plasma physics expcriments in November of 1988. In parallel, a series of FELs were designed and two different FELs supplied 140 $\mathrm{GHz}$ microwaves to the tokamak. These were the ELF, Experimental Laser Facility and the IMP, Intense Microwave Prototype. The $140 \mathrm{Ghz}, 0.5 \mathrm{MW}$ Gyrotron which was the master oscillator for the FEL also supplied $140 \mathrm{GHz}$ microwaves to the MTX.

The same frequency, similiar plasma conditions, and the same transmission system would be used in this tokamak to show the differences in performance and operation of the conventional microwave heating of Gyrotrons and the unexplored alternative of the FEL. Both of these approaches intense power pulses of the FEL were expected to be nonlinearly absorbed, that is, less effectively than the longer length, lower power of the Gyrotron. The FEL operations proved that the nonlinear effects were observable and repeatable and intense pulses could be controlled and modified to approach the linear absorption of lower power microwaves. With the success of this first FEL ECRH, further development of this alternative technology is now possible for electron heating and for current drive methods.

\section{OVERALL DESCRIPTION}

\section{ETA-II Accelerator}

The electrons are injected from a cathode that produces 2-3 kA for 50 nanoseconds of electrons at 1-1.5 $\mathrm{MeV}$. These were focused and acclerated to $6 \mathrm{MeV}$. Engineering development in the power supply regulation, insulator technology, magnetic alignment diagnostics, and controls over the lifetime of ETA-II accomplished the reduction of corkscrew motion by a factor of 10 to $+/-1.5$ $\mathrm{mm}$. This resulted in a consistent transport of the 2 to 3 kAmps of current to the entrance of the FEL. Details of the upgrades which allewed this improvement are contained in the references 1,2 .

\section{MW system}

The Microwave System consisted of a Master Oscillator, a Varian Gyrotron Tube, $140 \mathrm{GHz}, 400 \mathrm{~kW}$ peak power , $1 / 2$ second pulse length, a waveguide, 2 viasov launch , focusing and alignment mirrors, a "Side Coupler", and forward and reflected microwave power diagnostics References contain many more details of the MW system and the Gyrotron operation. ${ }^{3}$

Arcs eliminated with patented sealing method. The waveguide sections were joined with a patented sealing method that accomplishes metal to metal contact and a smooth surface transition between the two flanges on the different waveguide components. A minimum of disruption of the waveguide wall surface is accomplished by the method. The successful running of the system at air and at vacuum proved out the worthiness of the flange system. No arcs were evident when running at a vacuum of $1 \mathrm{e}-5$ Torr at the entrance of the waveguide. Vacuum at the window was estimated to be 1e-4 Torr or greater. Two miter bends were used as were three lossy waveguide sections in areas where trapped modes were pessible. 
A Vlasov launch to a series of large (17 by 23 inch) aimable, aluminum mirrors, inside 20 inch diameter vacuum vessels brought the microwave beam into co-linearity with the electron beam at the Side Coupler. The Side Coupler was an electron beam pass through device and a mirror at a $\mathbf{4 5}$ degree angle with respect to the microwave beam. Co-linearity with the electron beam was needed prior to entrance into the FEL.
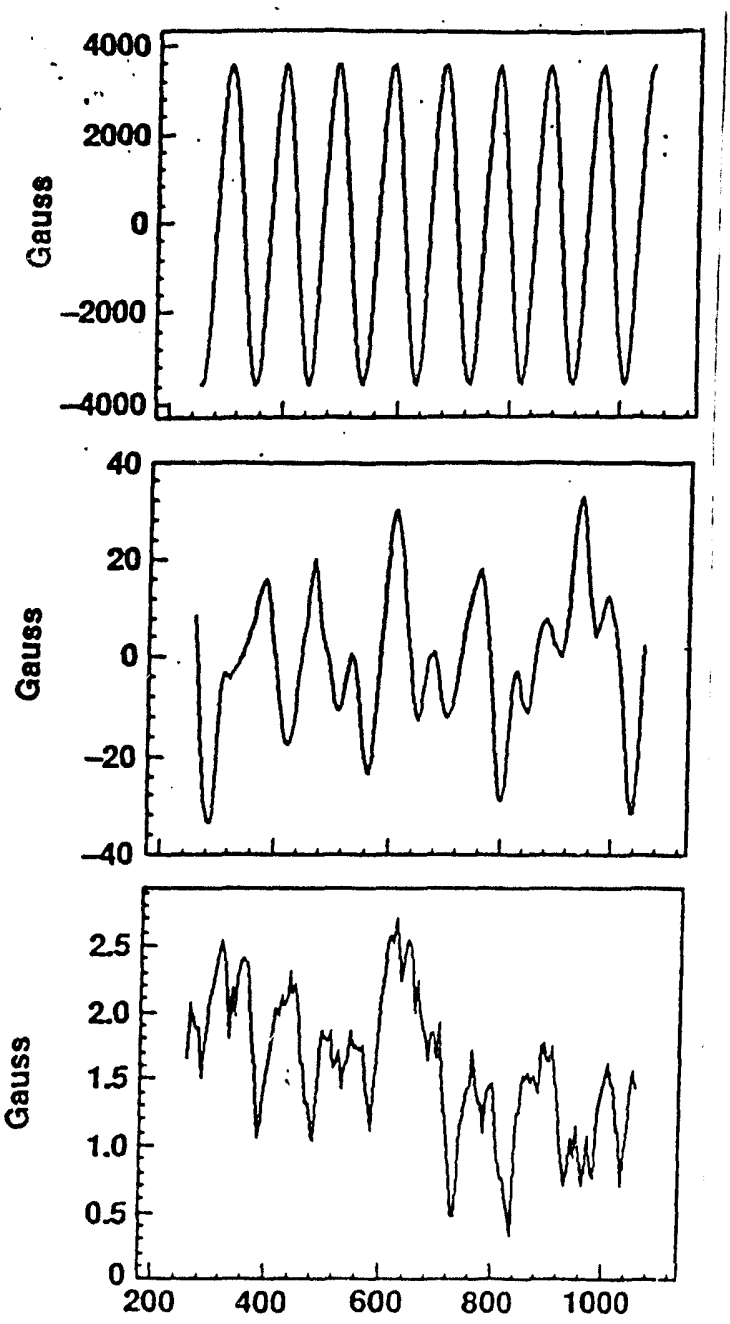

FIGURE 1. Top plot: Wiggler field, $B_{\text {fit }}$ or $B_{\text {data }}=f(z)$.. Middle plot: $B_{\text {data }}-B_{\text {fit }}=$ Large errors correlated to permanent magnet locations. Bottom plot: $B_{\text {data }}-B_{\text {fit }}=$ correlated errors reduced, dominant errors are random.

\section{IMP FEL Wiggler}

The IMP FEL was originally a Strategic Defense Initiatives Organization project item. It was modified and upgraded for use in fusion as a $140 \mathrm{GHz}$ amplifier. The IMP FEL has been described in various publications but the major references are included in the end of this paper ${ }^{4} .^{5}$

The IMP was divided into Upstream (Higher magnetic field strength) and Downstream (lower magnetic field stregnth) sections. The characteristics of the wiggler are

\section{$10 \mathrm{~cm}$ period}

Upstream: 2700 to 5500 gauss linear opertional range

Upstream length 2.2 meters

Downstream: 600 to 4100 gauss linear opertional range

Downstream length 3.45 meters

112 poles

4 electromagnets per pole

112 electromagnets (4 poles per electromagnet)

Errors in a wiggler are the most important factor in determining success. A perfect sinusoidal field profile would have zero errors. Imperfections produce errors. Correlated errors, those tracable to physical characteristics, must be reduced or eliminated and uncorrelated errors, random in nature and untracable, must be low enough so that the electron beam will not grow too large and strike the beam tube.

To obtain an estimate of the errors a magnetic scan is made of the entire length of the wiggler. The data is fit to a fourier series expansion of the form

$$
B_{f i t}=\sum_{1}^{9} b_{n} \times \cos \left\{\frac{2 \pi \cdot n}{\lambda_{\omega}}\left(z-z_{n}\right)\right\}
$$

The difference between the data and the perfect fit is called the residuals.

$$
\text { Residuals }=B_{\text {data }}-B_{f i t}
$$

The RMS of the residuals are divided by the peak magnetic field value and represented in percentage form as

$$
\text { Errors } \%=\frac{\text { RMS }_{\text {Residuals }}}{\text { Peak B field value }} \%
$$

The effort to reduce the errors required understanding and attention to the details of the construction, assembly, debug of minor details and modifications of the permanent magnet design. The low value of the errors at $0.19 \%$ cannot adequately represent the hard work of many talented people. It was a major accomplishment and permitted the successful operation of the FEL. Figure 1 shows representative data.

\section{Transmission System}

The Microwave Transmission system was originally installed and used for the first FEL to make and deliver 140 $\mathrm{GHz}$ microwaves to the MTX. It consists of a series of large aluminum mirrors of the same type used on the Microwave System described earlier. These mirrors had to propigate the FEL generated linearly polarized microwave beam to the MTX. A specific alignment and angular arrangement brought the beam into proper orientation with the magnetic field of the tokamak and for absorption in the plasma. The mirrors went through several generations of development. The final set allowed for a repeatable and removable visible laser alignment system to be used prior to microwave alignment. Details of the Transmission System are contained in the references. ${ }^{6}$

\section{$M T X$}


An overview of the MTX operation and developments was given in the proceedings of the previous IEEE/NPSS, 14th Symposium on Fusion Engineering. ${ }^{7}$

\section{Major Radius \\ Minor Radius \\ Peak magnetic field operation \\ Normal mode for FEL operations \\ Electron density \\ Plasma currents operated in the}

\author{
0.64 meter \\ 0.165 meter \\ 9 Tesla \\ 5 Tesla. \\ $5 \mathrm{e}^{-19} \mathrm{~m}^{-3}$ range \\ $200 \mathrm{kAmp}$ range
}

Diagnostics: Extensive diagnostics were installed on the MTX for the purpose of diagnosing the effects of the various microwave power on the plasma. A brief list of them includes a nine channel Michelson ECE waveguide polychromator, a four channel ECE microwave reciever system to measure the hot electon emission from ECH heating, a 15 channel interferometer, a two channel O-mode reflectometer, and a particle probe diagnostic for determining the FEL electric field strength inscide the plasma. The majority of the diagnostics were for the determination of the ECH effects of the FEL on the plasma. A detailed discussion is contained in the references 8 .

\begin{tabular}{|c|c|}
\hline \multicolumn{2}{|c|}{ OPERATIONS AND RESULTS } \\
\hline \multicolumn{2}{|l|}{ Accelerator } \\
\hline Beam energy & $6 \mathrm{MeV}$ \\
\hline Beam current & 3000 amps maximum \\
\hline Beam corkscrew & $<1.5 \mathrm{~mm}$ \\
\hline Beam duration & 50 nanoseconds / pulse \\
\hline & 50 pulses maximum \\
\hline Microwave Input to & \\
\hline Input Power & $\begin{array}{l}7 \mathrm{~kW} \text { at FEL entrance } \\
100 \text { mili-second duration for } \\
\text { experiments }\end{array}$ \\
\hline $\begin{array}{c}\text { FEL Microwave } O \\
2 \mathrm{GW} \text { Peak at FE } \\
1 \mathrm{GW} \text { typical at } \\
20-30 \text { nanosec }\end{array}$ & Power \\
\hline
\end{tabular}

\section{Electron Beam into the FEL}

The electron Beam was brought into the FEL through the use of magnetic lenses which allowed the larger beam to be focused into the proper size for the FEL. A $3.25 \mathrm{~cm}$ diameter waveguide / beamtube was filled radially to $50 \%$ with the energetic electron beam. A visual alignment method was used for the first passage of the beam through the FEL. A quartz foil in the beamtube was imaged into a remoted camera. The proper focusing of the beam for the best overall transport characteristics in the FEL took several days. Both betatron motion and sausage like behaviour of the beam were minimized. Figure 2 is a manipulated centroid view which shows the IMP FEL. electron motion in the wiggle plane. Magnet settings in the transport system reproduced very well and permitted the successful FEI, operation.

\section{Electron Beam and MW into FEL.}

FEL operation began after the removal of the visual foil and optics. Microwave power of approximately $7 \mathrm{~kW}$ was incident upon the entrance of the FEL. A diagnostic microwave X-Y scan at the exit of the FEL without electron beam operation confirmed the proper microwave mode through the wiggler. It was upon this microwave input signal that the FEL would build.

The operation with electrons had several distinct phases.

First phase was the search for resonance. A short length of wiggler (1.6 meters) was set at a magnetic value below theoretical resonance. The microwave power was cycled on/off to determine if amplification was occuring. The magnetic field value was slowly raised until a definite increase in power occured. Repeated tests showed consistent operational magnetic field values. Previous experiments ${ }^{9}$ guided the methods used for obtaining resonance.

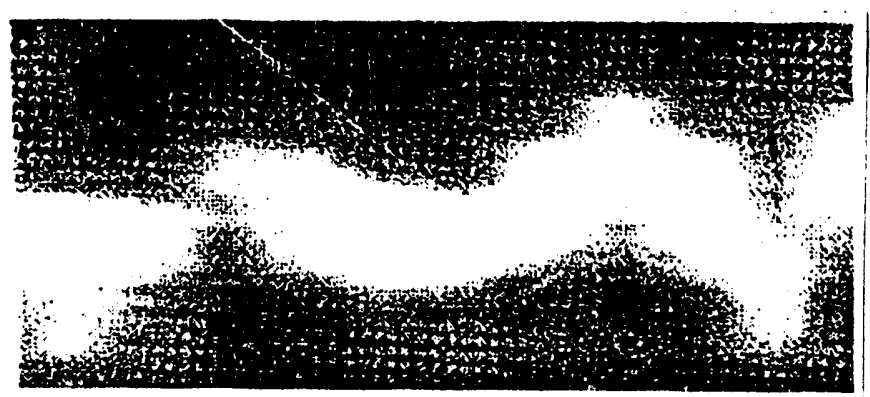

FIGURE 2. IMP FEL electron motion in wiggle plane. A plot of the central line scan of a series of images taken as the electron beam impinged on an alignment foil being moved through the wiggler. The horizontal axis is not monotonically increasing.

Second phase was the search for the maximum exponential gain length. Once the magnetic resonance had been established the length of the FEL magnetic field was increased to peak the power output. Once past that maximum field length the power drops if the field is left at the initial resonance value. This maximum length is called the exponential gain region.

Third phase was the search for the proper taper after the exponential gain length to remove the most power possible from the electron beam. This tapered magnetic field is refered to as the linear gain region. A linearly decreasing magnetic field over several pole lengths accomplished the final power extraction from the electron beam. Additonal time could have produced higher gain (theoretically up to 6 GW) but limited experimental time did not permit the continued exploration of alternate profiles for the taper in the linear gain region.

Amplification by the FEL produced peak pulse values at $2 \mathrm{GW}$. Figure 3 shows a $2 \mathrm{GW}$ signal detected by the diagnostic at the exit of the FEL. Typicai operation was at $1 \mathrm{GW}$.

After the shutdown of MTX the FEL was run in a burst mode to evaluate the feasibility of using the microwaves generated in future fusion applications as an intense ECH method or as a current driver. Though the current drive applications could not be explored in the MTX the technology of making multiple pulses was established. Figure 4 shows how a burst of $5($ ) electron pulses were amplified by the FEL 
and produced 28 microwave pulses. The FEL dropout could have been reduced by increasing the electron beam energy, changing the timing targets for each pulse of the burst, or adjusting the number of caps in the injector bank to compenste for the energy changes in the other power supplies, or by dropping the current.

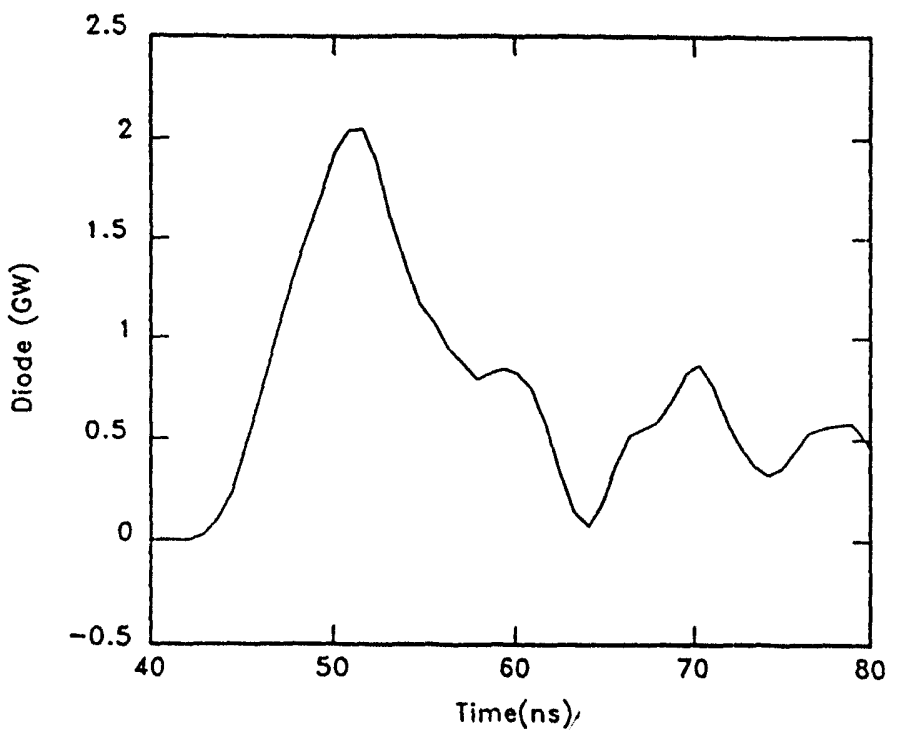

FIGURE 3 IMP FEL Peak power of $2 \mathrm{GW}$ detected at output of FEL.
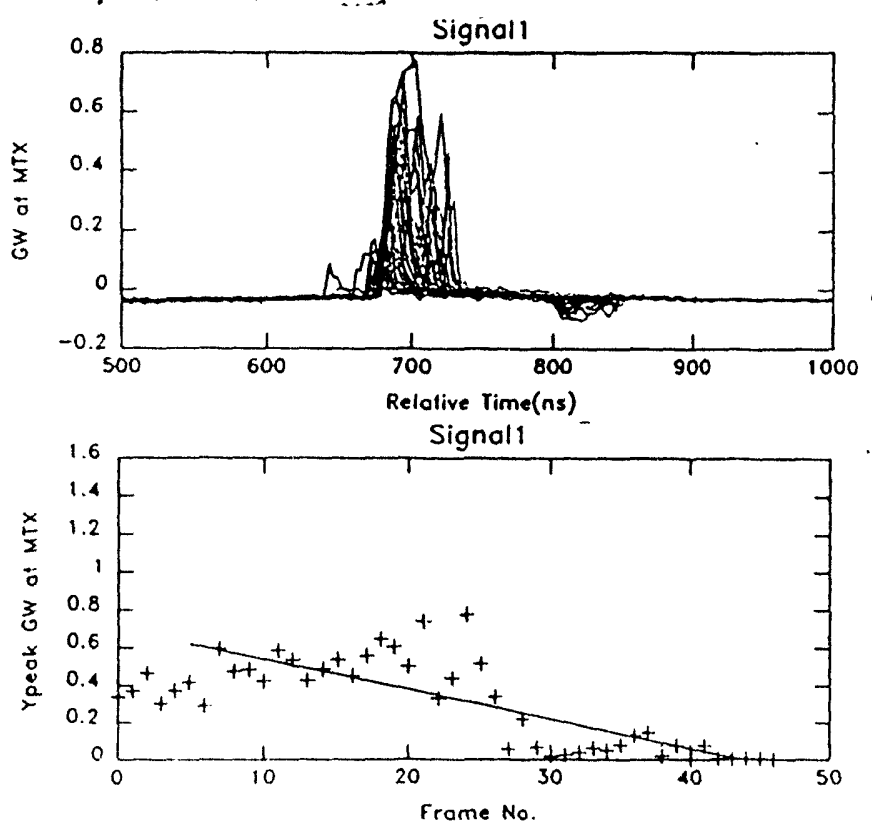

FIGURE 4. IMP FEL Burst Mode: 28 microwave pulses out of 50 electron pulses at $2 \mathrm{kHz}$.

The transmission system effeciency of $89 \%$ broght the majority of the power to the MTX.

The absorption and transmission data of the microwave in the plasma and the variations on how control of the polarization affected them are presented in the references. 10 The body of knowledge of the linear and nonlinear effects of microwave heating has been expanded. Briefly stated the un-modified intense pulses had higher transmission in the MTX plasmas as compared with the lower power gyrotron pulses. Control of the transmission (increased absorption) was obtained by modifying the polarization of the microwave as it entered the MTX. This was accomplished by placing a corrugated surface on the entrance port walls into MTX. Increased absorption of the IMP pulses was accomplished and near linear absorption data was obtained also with intense pulses

These results clearly indicate that an effecient, windowless, quasi-optical, polarization controlled transmission of intense microwaves has been achieved. The benefit for future experiments is that power limits have been raised by the removal of windows. Antennas for ECH can be far away from the plasmas, where they are insensitive to plasma edge conditions. ECH methods have been expanded with the polarization contrcl.

*This work was performed under the auspices of the U.S. Department of Energy by Lawrence Livermore National Laboratory under contract number W-7405-ENG-48.

1S. L. Allen, E. T. Scharlemann, The ETA-II Linear Induction Accelerator and IMP Wiggler: A High-AveragePower Milimeter-Wave Free-Electron-Laser for Plasma Heating, 9th International Congerence on High-Power Particla Beams, Washington, DC May 25, 1992

${ }^{2}$ D. G. Nilson, et al, ETA-II Acceleatory Upgrades, ,IEEE/NPSS 14th Symposium on Fusion Engineering, SanDiego, California, October 3, 1991

${ }^{3} \mathrm{~S}$. W. Ferguson, et al, Installation and Operation of the $400 \mathrm{~kW} 140 \mathrm{GHz}$ Gyrtron $\mathrm{n}$ the MTX Experiment, IEEE/NPSS 14th Symposium on Fusion Engineering, SanDiego, California, October 3, 1991

${ }^{4} \mathrm{~S}$. Allen et al, Nonlinear Absorption of High Power FEL-Generated Microwaves at ECRH Frequiencies in the MTX Tokamak, March 1993 Physics Review

${ }^{5} \mathrm{~B}$. Felker, The Intense Microwave Prototype(IMP) Free Electron Laser, 140 Gigahertz Micreowave system for the Microwave Tokamak Experiment(MTX), IEEE/NPSS 14th Symposium on Fusion Engineering, SanDiego, Califomia, October 3, 1991

${ }^{6}$ B. Felker, S. W. Ferguson, Microwave Transport System of the MTX, , IEEE 13th Symposium on Fusion Engineering, Knoxville, Tennessee, October 2-6, 1989, UCRL-101 184, Lawrence Livermore National Laboratory

${ }^{7}$ D. D. Lang, et al, Overview of the Micowave Tokamak Experiment Operation and Developments, IEEE 14th Symposium on Fusion Engineering, SanDiego, California, October 3, 1991,

${ }^{8}$ D. Nilson, et al, Diagnostic Upgrades on MTX, IEEE 14th Symposium on Fusion Engineering, SanDiego, California, October 3, 1991

${ }^{9}$ ELF results, T. Scharlemann, daily communication throughout IMP operations.

${ }^{10} \mathrm{~S}$. Allen et al, Nonlinear Absorption of High Power FEL-Generated Microwaves at ECRH Frequiencies in the MTX Tokamak, March 1993 Physics Review 


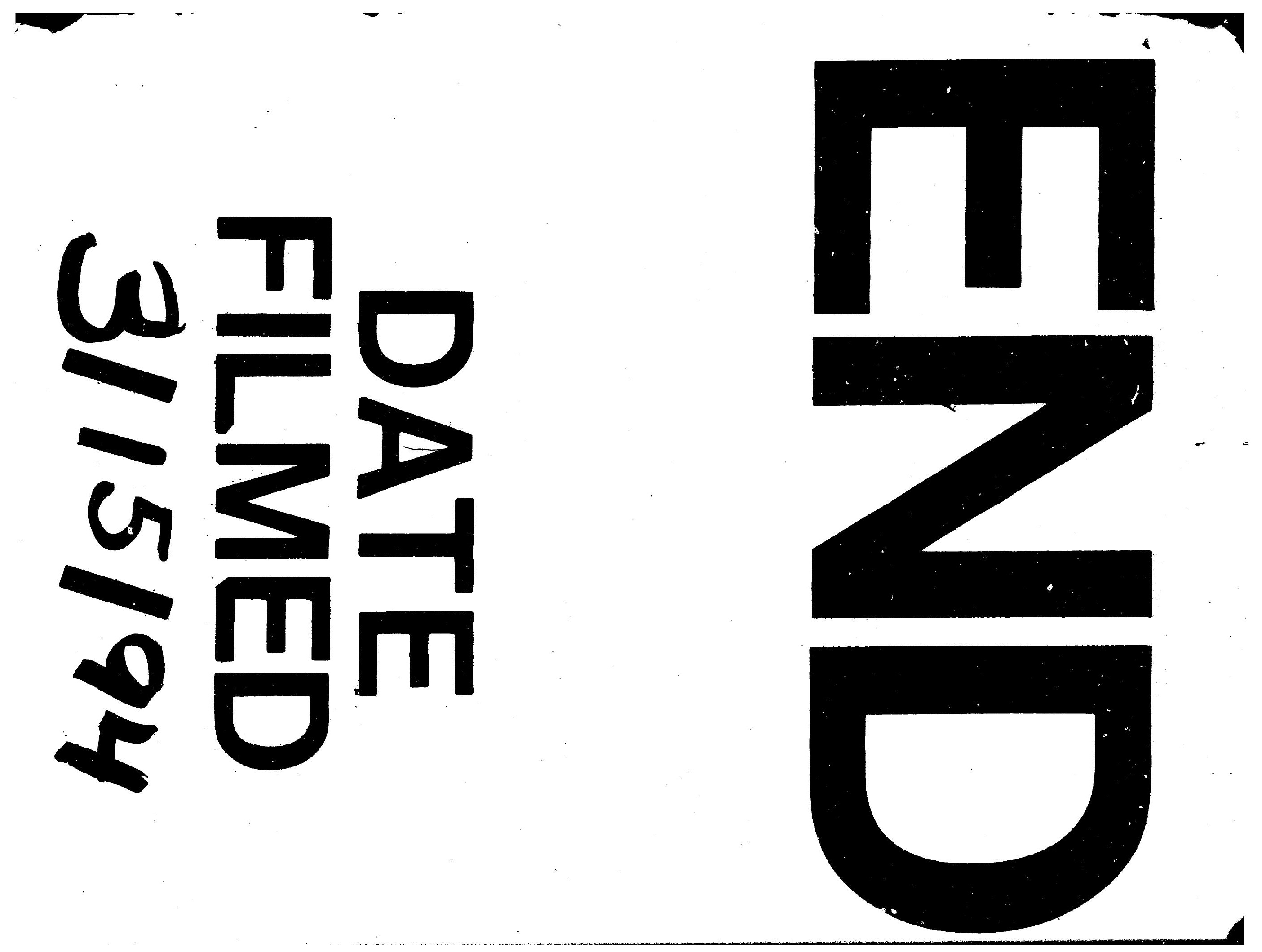




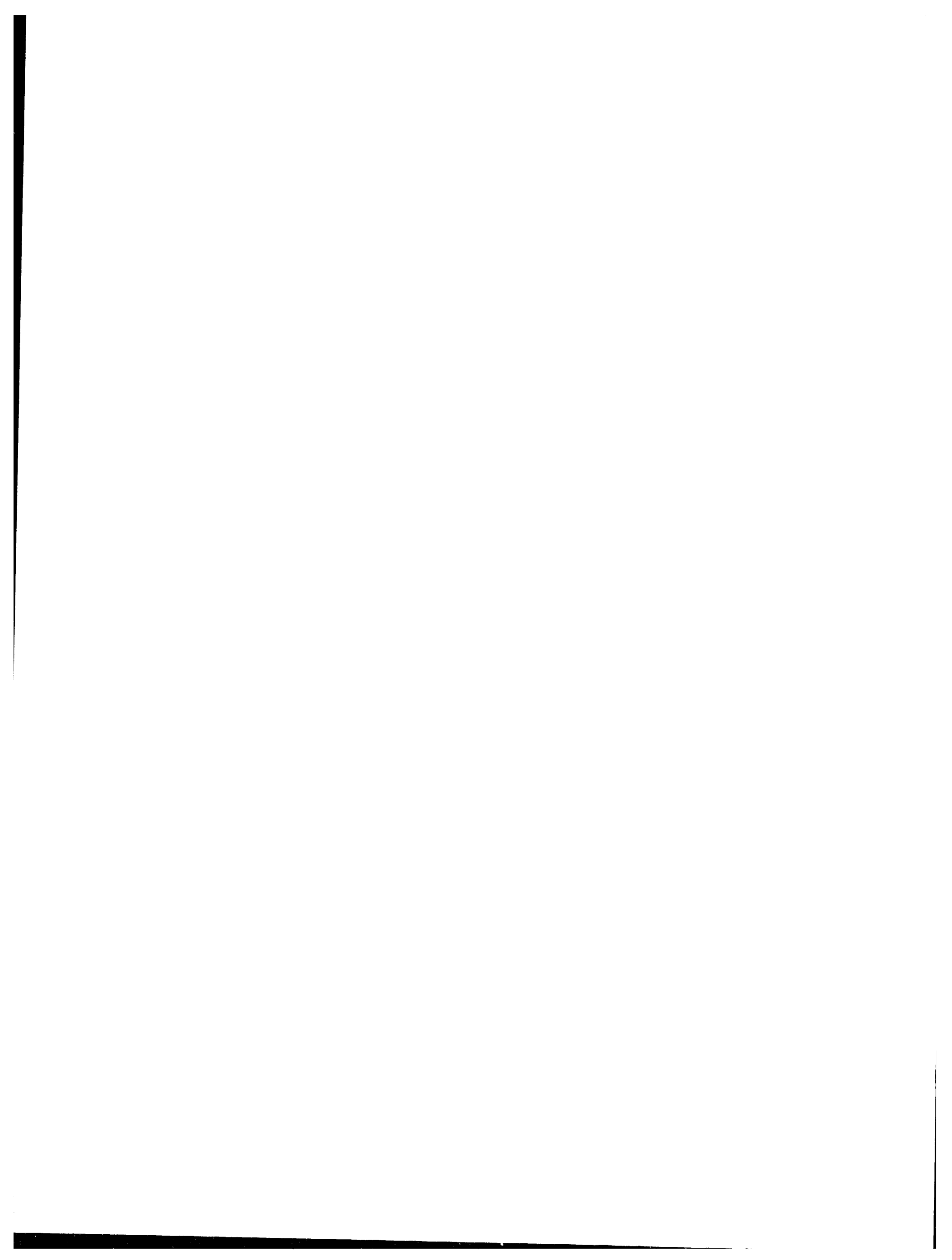

